\title{
What matters for patients' experiences with primary care? A study of variation in patient reported experience measures with regard to structural and organisational characteristics of primary care centres in a Swedish region.
}

\author{
ANNA HÄGER GLENNGÅRD ${ }^{1 *}$ \\ ${ }^{1}$ Lund University School of Economics and Management, Sweden
}

\begin{abstract}
Previous research on variation in patient reported experience measures (PREMs) suggest that it is important to be cautious when using comparative information about patients' experiences, collected via patient surveys, to assess provider performance. Not all factors associated with variation in PREMs are related to factors that providers themselves can control. This study explores if structural characteristics of primary care practices (PCCs), that are difficult to control, and the way that providers manage and organise their work matter for patients' experiences with care. The purpose was to analyse variation in PREMs at the PCC level in Swedish primary care, with regard to structural characteristics of PCCs, including patient mix, and variables representing how providers organise and manage their work. Since the choice reform in 2007-2010, there is a mix of public and private providers, all with public funding and operating under the same overall requirements. The analysis is based on data from a national patient survey in primary care and registry data from a large Swedish region. OLS regression analysis was used to study variation in seven PREM-dimensions in regards to variables representing structural and organisational characteristics and processes of work at PCCs, covering the years 2018-2019 ( $\mathrm{N}=281$ PCC year observations). The results imply that variables that can be changed by providers themselves matter more for patients' experiences with care than factors that providers cannot control. The most significant associations were found between PREMs and proportion and continuity of GP visits and adherence to clinical guidelines regarding treatment of risk groups. However, it is a challenge for providers to offer a high proportion of visits with GPs and good continuity due to a persisting shortage of GPs in Sweden. Recent policy initiatives have been introduced in this area. From a policy perspective, variation in patients' experiences with regard to socioeconomic conditions is also a concern.
\end{abstract}

JEL classification: I11, I14, I18

Key words: PREM, responsiveness, welfare market, primary care, performance measures

* Correspondence to: Anna Häger Glenngård, Lund University School of Economics and Management, Box 7080, SE-220 07, Lund, Sweden. Email: anna.glenngard@fek.lu.se.

Published: Online August 2021. dx.doi.org/10.5617/njhe8030 


\section{Introduction}

Primary healthcare is that level of a healthcare system which "provides entry into the system for all needs and problems, provides person-focused (not disease-oriented) care over time, provides care for all but very uncommon or unusual conditions, and coordinates or integrates care provided elsewhere by others" (Starfield 1998, p 9). Strengthening primary care is commonly regarded as vital in enhancing equity and efficiency in healthcare systems (Scott 2000; Saltman et al 2006). Similar to the development in the United Kingdom (UK), the development in Sweden during the past decades has been to expand primary care as hospitals and beds are cut back (Anell et al. 2012; Ewbank et al. 2017; Lövtrup 2017). In both countries, reductions are due to long-term policies to move patients out of hospitals towards primary and community-based care, and to the pursuit of patient-centred care. Patient-centred care implies the provision of care that is respectful of, and responsive to, individual patient preferences, needs and values (Institute of Medicine 2001). In 2007-2010, a choice reform was gradually introduced in Swedish primary care, targeted particularly at problems with poor accessibility, continuity and responsiveness of primary care, ideally without negative consequences for equity (Anell 2011; Glenngård 2016). Since the introduction of the choice reform, primary care is organised in a welfare market with free choice of primary care practice (PCC) for individuals and competition among public and private PCCs.

Information about patients' perceptions about different dimensions of care are commonly collected by the use of patient surveys. Based on results from a patient survey covering 32 countries, Murante et al (2017) conclude that in 2011-2013 the responsiveness of primary care was (still) lower in Sweden compared to other similar countries. Since 2009, a national patient survey (NPS) is administered annually to a sample of patients having visited each PCC in Sweden. The results from the NPS are summarised into different patient reported experience measures (PREMs) at the PCC level, e.g., overall impression, responsiveness and accessibility. This information is publicly available to citizens with the intention of facilitating informed choices of PCCs among individuals. It is also used by the regions, responsible for the organisation and financing of healthcare in Sweden, to assess provider performance. Results from previous studies about variation in patients' experiences, based on NPS data in Sweden (Angelis et al 2021; Glenngård 2013; Glenngård and Anell 2017; 2018; Kandelake 2016), are largely in line with findings from similar studies in other settings (Kontopantelis et al. 2010; Campbell et al. 2001a; 2001b; van den Homberth 2016). The size of PCCs matters: Patients tend to be more satisfied with smaller practices. The organisation of work matters: PCCs where general practitioners (GPs) handle a large proportion of all visits tend to perform better, not least with regard to continuity. Patient mix also matters for patients' experiences with care, according to previous studies. PCCs serving a population with high socioeconomic deprivation tend to perform worse. A negative correlation between high socioeconomic deprivation and PREMs has been reported in several articles based on Swedish NPS data (Angelis et al 2021; Glenngård 2013; Glenngård and Anell 2017; 2018; Kandelake 2016). Regarding the morbidity of patients, the evidence is mixed. A Dutch study (van den Homberth et al 2016) report that having no chronic disease is associated with better experiences with care. The same study reports that higher age is associated with better experiences, which is somewhat contradictory as higher age is typically correlated with higher prevalence of chronic illness. Previous studies based on Swedish NPS data (Glenngård 2013; Glenngård and Anell 2017; 2018) show that a high average morbidity among individuals on the PCC list, quantified by grouping individuals based on their age, gender and the constellation of diagnoses in out-patient care, is correlated with better patient experiences. Ownership also seem to matter: Private PCCs perform better 
than public ones with respect to several dimension of patients' experiences, according to results from the Swedish NPS for the years 2010-2014. When adjusting for patient mix, the organisation of work and PCC list size, such differences do not remain for most dimensions (Glenngård 2013). Finally, the processes of work at each PCC matter for patients' experiences. Based on an analysis of NPS data from 2012-2013 and process measures derived from two Swedish regions, Glenngård and Anell (2017) conclude that patients' experiences are positively correlated with better adherence to clinical guidelines regarding treatment of elderly and risk groups and prescription of pharmaceuticals. Previous research on hospitals show that management practices affect the ability to respond to patients' needs and expectations in a cost- effective manner (Prentice et al 20007; Bloom et al, 2015). To what extent the quality of management at PCCs is related to better or worse patient experiences is largely unexplored. One study, based on the World Management Survey tool (Bloom and van Renen 2007) and data from the 2014 NPS find no correlation between patients' experiences and management quality (Angelis et al 2021).

Results from previous research suggest that it is important to be cautious when using PREMs to assess the performance of providers. In Swedish primary care, the regions use indicators reflecting adherence to evidence-based clinical guidelines, other clinical process measures and PREMs to assess provider performance (Fredriksson et al 2014; Glenngård 2019). With regard to PREMs, clearly not all factors that are of relevance to how providers perform, according patient surveys, are related to actual differences in how providers organise and manage their work. Structural characteristics, such as size of PCCs and patient mix, are also correlated with PREMs (Angelis et al 2021; Glenngård 2013; Glenngård and Anell 2017; 2018; Kandelake 2016; Kontopantelis et al. 2010; Campbell et al. 2001a; 2001b; van den Homberth 2016). Providers have limited possibilities to control the PCC list size and the patient mix with other means than choice of location. By law, providers cannot deny an individual from enrolling at the PCC list (Health and Medical Services Act 2017:30). This adds to the complexity of payers using such information to assess and hold providers to account for their performance. Moreover, if variation in PREMs mirror structural differences of PCCs rather than differences in provider behaviour, such information may not serve the purpose of helping individuals making an informed choice of PCC.

\subsection{Purpose}

The purpose of this study was to analyse variation in PREMs at the PCC level in Swedish primary care, with regard to structural characteristics of PCCs and variables representing how providers organise and manage their work. Most previous research on variation in patients' experiences and its policy implications in this setting is based on data from the years immediately following the choice reform. This study sets out to explore this topic based on data ten years after the introduction of choice and competition. The structure of Swedish primary care, with free choice of PCC for individuals and competition among public and private providers, is intended to enhance the responsiveness of care towards patients through market mechanisms (Le Grand 2009; Propper 2012). Moreover, a tradition of team-based primary care and fixed payment to PCCs theoretically gives providers good opportunities to organise and manage PCCs in accordance with their specific conditions, as the level of professional autonomy is high and a flexible use of resources is encouraged (Yarnall 2009; Jessup 2007; Barnum et al 1995). This makes Swedish primary care an interesting setting to explore if structural characteristics of PCCs, that are difficult for providers themselves to control, and the way that providers manage and organise their work matter for patients' experiences with care. 


\section{Data and Methods}

\subsection{The setting}

Swedish healthcare is highly decentralised. The responsibility for financing and organisation of healthcare rests with 21 independent regions while the central government is responsible for overall healthcare policy and legislation. Primary care expenditures constitute about one fifth of total healthcare expenditures. The share varies slightly between regions. There are about 1200 PCCs in Sweden. About 40 percent are privately operated. Private providers are predominately for profit (Glenngård 2019). The principle of teambased primary care is expected to shorten waiting times and improve services through the substitution of GP labour input for non-GP labour input, such as nurses, whereby GPs can devote more time to patients with severe problems (Yarnall 2009; Jessup 2007). PCCs typically consists of 40-70 staff with a mix of professional competencies, e.g., GPs, nurses with different specialisations and physiotherapists. The specific requirements that providers have to comply with to be allowed to practice care with public funding differ between regions in accordance with local political considerations and priorities. The same requirements apply to public and private providers in each region (Health and Medical Services Act 2017:30). The use of indicators to assess provider performance and hold providers to account for their adherence to requirements stipulated in contracts differ between regions, as a consequence of the decentralised healthcare system. Most regions use proxy measures related to the framework "Good healthcare and social services". It was developed by The Swedish National Board of Health and Welfare in 2006, inspired by the Institute of Medicine in the US (National Board of Health and Welfare 2009; Institute of Medicine 2001). The framework contains six domains: The care provided should be: patient-centred, knowledge-based, safe, accessible, efficient and equitable.

\subsection{The case}

The analysis is based on data from the third largest region in Sweden; Region Skåne, with a population of around 1.3 million. There are 33 municipalities in the region. The largest, in terms of population size, is the residence city of Malmö with about 300000 inhabitants. Region Skåne offers an interesting case to study variation in patients' experiences due to variation in structural and organisational characteristics of PCCs and access to data about such variables at the PCC level.

There are about 150 PCCs in the region. Contracts are signed between a contract manager at the region and the managing director of each PCC. They are formally valid for two years, but as long as PCCs meet the financial, organisational and quality requirements as specified by Region Skåne they are automatically renewed. Payment to PCCs is based on fixed capitation, risk-adjusted for expected greater care need related to morbidity (measured by adjusted clinical groups, ACG) and social deprivation (measured by care need index, $\mathrm{CNI}$ ) among individuals on the PCC list. ACG quantifies morbidity by grouping individuals based on their age, gender and the constellation of diagnoses over a defined time period (Reid et al 1999), 18 months in the case of Region Skåne. CNI is a measure of social deprivation related to seven factors, e.g., education and unemployment (Sundquist et al 2003).

Different performance measures are used to assess PCCs with regard to adherence to stipulated requirements. Region Skåne operationalise the framework "Good healthcare and social services" through performance data from their administrative systems, electronic patient records and from two national surveys: the NPS and the national waiting-time survey (Region Skåne 2018; Appendix 1). 


\subsection{Data}

A fairly broad set of independent variables were used to analyse variation in seven PREMdimensions at the PCC level. The choice of variables was based on availability and reliability of data and assumptions about what factors might have an impact on patients' satisfaction in welfare markets in primary care. Independent variables were derived from previous research about variation in patient satisfaction in Swedish primary care (Angelis et al 2021; Anell 2011; Glenngård 2013; Glenngård and Anell 2017; 2018; Kandelake 2016) and other comparable settings (Kontopantelis et al. 2010; Campbell et al. 2001a; 2001b; van den Homberth 2016). Two types of independent variables were included in the analysis:

- Variables representing structural characteristics of PCCs, that are difficult for providers themselves to control; and

- variables representing organisational characteristics and processes of work at each PCC, that to a higher extent are possible for providers themselves to control.

Data on PREMs was derived from the NPS in primary care. Data on structural and organisational characteristics and processes of work was derived from registers in Region Skåne. The region collects and stores data on characteristics of PCCs, volumes of care and adherence to requirements stipulated in contracts to inform payments and monitor PCC performance. Data from the different sources was linked by the names of PCCs.

\section{Dependent variable: PREM-dimensions}

The NPS is a national survey administered by mail to a random sample of patients having visited a PCC during the autumn each year in all participating regions. The administration of the survey and the calculation of PREM-scores for each individual PCC is led by the Swedish Association for Local Authorities and Regions (Swedish Association for Local Authorities and Regions 2020). Results from the 2018 and 2019 NPS were used in this study. The 2018 survey was answered by 83229 individuals and the 2019 survey by 98992 individuals (response rates of $35,7 \%$ and $41,2 \%$ respectively) having visited a GP in September. In Region Skåne, 10398 individuals answered the survey in 2018 and 12514 in 2019 (response rates of $35,5 \%$ and 39,8\% respectively). The average number of respondents per PCC in Region Skåne was 70 (SD 25 respondents) in 2018 and 82 (SD 28 respondents) in 2019. The NPS contains background questions about the respondent and 32 Likert scale questions ( $1-5$, where $1=$ No, not at all and $5=$ Yes, fully) about their experience with the care provided. The questions are grouped into seven PREM-dimensions for each PCC: Overall impression, emotional support, patient involvement, respect and responsiveness, continuity and coordination, information, and accessibility. Each dimension is assigned a PREM-score between 0 and 100 based on the proportion of positive answers (3-5 o the Likert scale) to each question (see Swedish Association for Local Authorities and Regions 2020 for details on questions and composition of scores). These seven PREMscores, at the PCC level, were used as dependent variables in the regression models.

\section{Independent variables: structural characteristics}

Six variables were used to analyse variation in PREM-scores with respect to structural differences of PCCs:

- Ownership, defined as private or public PCC.

- Size, measured as the PCC list size in November each year. 
- Three variables were used to describe the PCC patient mix: average ACG, average CNI and proportion of enrolled that are 75 years or older. Regarding ACG and CNI, higher values imply worse overall morbidity and socioeconomic status, respectively. ACG and CNI measure the relative level of morbidity and socioeconomic conditions in a group of PCCs.

- As the aim was to analyse variation in performance attributable to differences among individual PCCs, dummy variables representing each of the 33 municipalities were included to control for variation attributable to structural differences due to location.

\section{Independent variables: organisational characteristics and work processes}

Five variables were used to analyse variation in PREM-scores attributable to differences in the management and organisation of work at each PCC:

- Two variables were used to reflect the management and division of labour: Professional background of managing director, defined as GP or other background, and the number of GP visits as a proportion of all visits.

- Two proxy measures were used to describe productivity levels: The average number of visits per enrolled and the average number of weighted visits (GP visits $=1$; all other visits $=0.4$ (National Board of Health and Welfare 2020)) per enrolled. Higher values indicate higher productivity levels.

- One proxy measure of efficiency was used: The amount paid to each PCC by the region divided by the number of weighted visits produced, i.e., the cost per visit for the payer. Higher values indicate a lower level of efficiency (higher cost per visit).

Five proxy measures, representing the working processes at each PCC, were used in the regression models. These process measures focus on the adherence to evidence-based guidelines for different patient groups and are used by Region Skåne to assess performance in the dimensions preventive care and safety (see Appendix 1):

- The continuity in GP visits, defined as the proportion of patients (0-100\%), among those with more than three visits during six months, who get to see the same GP in at least 50 percent of the visits.

- The annual influenza vaccination coverage (0-100\%) among individuals who are 65 years or older. A higher number indicates better adherence to treatment guidelines.

- The number of daily doses of harmful drugs (DDD) among patients aged 75 or older. A lower number indicates a better adherence to prescription guidelines.

- The proportion quinolones of all penicillin prescribed to women with lower urinary tract infection (UTI) (0-100\%). A lower number indicates better adherence to prescription guidelines. The target is $<10$.

- The proportion of penicillin $\mathrm{V}$ of all penicillin prescribed to children aged 6 years or younger with respiratory illness (0-100\%). A higher number indicates better adherence to prescription guidelines.

\subsection{Statistical analysis}

First, mean values were used to describe characteristics and performance of PCCs. Second, bivariate correlation analysis was used to analyse variation between two variables at the time. The seven PREM-dimensions were analysed with respect to the factors representing structural and organisational characteristics and processes of work at PCCs. Third, OLS regressions carried out in SPSS (version 22) was used to study variation in PREM-scores at the PCC level, taking several factors into account simultaneously. A cross-sectional design 
was used whereby the dependent variable in each regression model was defined as PCC year observations of PREM-scores for each PREM-dimension. Robust standard errors were used in all models. The choice of final models was done with respect to the model with the highest value of explained variance of the dependent variable (adjusted R2), controlled for multicollinearity between independent variables. Tolerance values below 0.25 and variance inflation factor (VIF) values $>4$ were not accepted (Pallant 2007).

\section{Results}

\subsection{Descriptive analysis of PCCs}

In table 1, descriptive statistics of the variables included in the bivariate analysis and regression models is presented.

Table 1: Characteristics and performance of PCCs in Region Skåne 2018-2019

\begin{tabular}{|c|c|c|c|c|c|}
\hline & & \multicolumn{2}{|c|}{$\begin{array}{l}2018 \\
(148 \text { PCCs })\end{array}$} & \multicolumn{2}{|c|}{$\begin{array}{l}2019 \\
(153 \text { PCCs })\end{array}$} \\
\hline & & mean & (S.D.) & mean & (S.D.) \\
\hline \multirow{5}{*}{$\begin{array}{l}\text { Structural } \\
\text { characteristics }\end{array}$} & Ownership (proportion private PCCs) & $43 \%$ & & $45 \%$ & \\
\hline & PCC list size & 8884 & $(3632)$ & 9134 & $(3735)$ \\
\hline & Patient mix: CNI & 1.00 & $(0.39)$ & 1.00 & $(0.40)$ \\
\hline & Patient mix: ACG & 1.00 & $(0.10)$ & 1.00 & $(0.10)$ \\
\hline & $\begin{array}{l}\text { Patient mix: Proportion of patients aged } 75 \\
\text { or above }\end{array}$ & $8.6 \%$ & $(3.1)$ & $9.5 \%$ & $(3.4)$ \\
\hline \multirow{5}{*}{$\begin{array}{l}\text { Management and } \\
\text { organisation of work }\end{array}$} & Productivity: Visits per enrolled & 3.02 & $(1.28)$ & 3.04 & $(1.07)$ \\
\hline & Productivity: Weighted visits per enrolled & 1.96 & $(0.78)$ & 1.95 & $(0.70)$ \\
\hline & $\begin{array}{l}\text { Background of managing director } \\
\text { (proportion GPs) }\end{array}$ & $22 \%$ & & $22 \%$ & \\
\hline & Division of labour: Proportion GP visits & $41.3 \%$ & $(10.0)$ & $41.1 \%$ & $(11.5)$ \\
\hline & $\begin{array}{l}\text { Efficiency: payment per weighted visit. } \\
\text { SEK }\end{array}$ & 1753 & $(372)$ & 1906 & $(429)$ \\
\hline \multirow[t]{5}{*}{ Processes of work } & Continuity in GP visits & $45.5 \%$ & $(14.0)$ & $49.5 \%$ & $(15.7)$ \\
\hline & Adherence, influenza vaccination coverage & $43.2 \%$ & $(8.5)$ & $48.0 \%$ & $(8.4)$ \\
\hline & Adherence, prescription of penicillin $\mathrm{V}$ & $79.8 \%$ & $(8.4)$ & $81.0 \%$ & $(8.5)$ \\
\hline & Adherence, prescription of quinolones & $8.0 \%$ & $(3.4)$ & $7.2 \%$ & $(2.5)$ \\
\hline & $\begin{array}{l}\text { Adherence, harmful drugs to elderly } \\
\text { (DDD) }\end{array}$ & 16602 & $(4663)$ & 23070 & $(7664)$ \\
\hline \multirow[t]{7}{*}{ PREM-scores } & Overall impression $(0-100)$ & 79.3 & $(6.9)$ & 79.9 & (7.4) \\
\hline & Emotional support (0-100) & 75.7 & $(7.6)$ & 76.8 & $(7.7)$ \\
\hline & Patient involvement $(0-100)$ & 78.3 & $(6.8)$ & 79.1 & $(6.5)$ \\
\hline & Respect and responsiveness $(0-100)$ & 84.0 & $(5.2)$ & 85.0 & $(5.0)$ \\
\hline & Continuity and coordination $(0-100)$ & 71.3 & $(9.0)$ & 72.0 & $(8.8)$ \\
\hline & Information $(0-100)$ & 74.2 & $(6.2$ & 75.6 & $(6.2)$ \\
\hline & Accessibility (0-100) & 81.0 & $(5.3)$ & 82.4 & $(5,3)$ \\
\hline
\end{tabular}




\subsection{Bivariate analysis of PREMs}

The results from the bivariate analysis between the different PREM-scores and characteristics of PCCs are reported in table 2. There are statistically significant negative correlations between most PREM-dimensions and size of the PCC as well as level of socioeconomic deprivation among enrolled individuals as measured by CNI. The opposite relation is found for overall illness as measured by ACG for three out of seven dimensions. There are statistically significant positive correlations between a high proportion of enrolled individuals aged 75 and above and the dimension "respect and responsiveness" and between private ownership and the dimension "continuity and coordination".

Regarding the variables reflecting the processes and organisation of work, there are statistically significant positive correlations between most PREM-scores and a high proportion of GP visits, that the managing director is a GP, a high continuity in GP visits and a high influenza vaccination coverage. There is a statistically significant positive correlation between a high number of weighted visits per enrolled and the dimension "accessibility". There is no statistically significant correlation between any of the PREMs included and variables reflecting adherence to prescription guidelines regarding antibiotics and harmful drugs to elderly or absolute number of visits per patient. Regarding the other proxy variables for productivity and efficiency, there is a statistically significant negative correlation between higher pay per weighted visit and the dimension "accessibility".

\subsection{Regression analysis of PREMs}

The final regression models are presented in table 3. Due to multicollinearity between average ACG and the proportion of individuals on the PCC list aged 75 and above, these two variables could not be included in the same models. Average ACG was not correlated with any PREM-dimension in the analysis when controlling for other factors and was therefore excluded from the analysis. Moreover, the productivity measures (weighted and absolute number of visits per enrolled) were excluded due to multicollinearity with the proxy measure of efficiency.

When controlling for several factors simultaneously, three variables, all representing the processes and organisation of work at the PCCs are correlated with the different PREM-dimensions. There are statistically significant positive correlations between all PREM-scores and a high continuity in GP visits as well as high influenza vaccination coverage. There is a statistically significant positive correlation between a high proportion of GP visits and six out of seven PREMscores. There is no statistically significant correlation between any of the PREM-scores and background of managing director or adherence to prescription guidelines. Lastly, there is a statistically significant negative correlation between the proxy measure of efficiency and one PREM-dimension: the higher pay per weighted visit the lower accessibility.

Overall, variables representing structural characteristics are not statistically correlated with PREM-scores when including variables representing how PCCs organise and manage the work. The significant relationship between private ownership and the dimension "continuity and coordination" found in the bivariate analysis disappears when including such variables. This implies that factors representing the organisation and processes of work, rather than ownership, are correlated with patients' perceptions about continuity and coordination of care. Moreover, while CNI was negatively correlated with almost all dimensions in the bivariate analysis, this statistically significant relationship remains only for the dimension "respect and responsiveness" when including variables representing how PCCs manage and organise their work in the analysis. The PCC list size is not statistically significantly correlated with any of the PREM-scores included in the regression analysis. There is a statistically significant negative correlation between a high proportion of elderly and PREM-scores for the dimensions "patient involvement" and "information". 
Table 2: Correlations between PREMs and different variables $(\mathrm{N}=293$ PCC year observations)

\begin{tabular}{|c|c|c|c|c|c|c|c|}
\hline & $\begin{array}{l}\text { Overall } \\
\text { impression }\end{array}$ & $\begin{array}{l}\text { Emotional } \\
\text { support }\end{array}$ & $\begin{array}{l}\text { Patient } \\
\text { involvement }\end{array}$ & $\begin{array}{l}\text { Respect } \\
\text { and } \\
\text { responsive- } \\
\text { eness }\end{array}$ & $\begin{array}{l}\text { Continuity } \\
\text { and } \\
\text { coordination }\end{array}$ & Information & Accessibility \\
\hline $\begin{array}{l}\text { Ownership } \\
\text { (Private=1) }\end{array}$ & 0.098 & 0.018 & 0.019 & 0.088 & $0.206^{* *}$ & 0.070 & 0.109 \\
\hline PCC list size & $-0.190 * *$ & -0.077 & -0.061 & $-0.146^{*}$ & $-0.167 * *$ & $-0.158 * *$ & $-0.347 * *$ \\
\hline $\begin{array}{l}\text { Patient mix: } \\
\text { CNI }\end{array}$ & $-0.236^{* *}$ & $-0.152 * *$ & $-0.120 *$ & $-0.329 * *$ & -0.077 & $-0.152 * *$ & $-0.121 *$ \\
\hline $\begin{array}{l}\text { Patient mix: } \\
\text { ACG }\end{array}$ & $0.164 * *$ & 0.054 & 0.015 & $0.150 * *$ & 0.067 & 0.058 & $0.167 * *$ \\
\hline $\begin{array}{l}\text { Patient mix: } \\
\text { Proportion on } \\
\text { list }>75\end{array}$ & 0.098 & 0.003 & -0.039 & $0.117^{*}$ & -0.055 & 0.013 & 0.105 \\
\hline $\begin{array}{l}\text { Productivity: } \\
\text { Number of } \\
\text { visits per } \\
\text { enrolled }\end{array}$ & -0.010 & -0.058 & -0.066 & -0.045 & -0.005 & -0.032 & 0.112 \\
\hline $\begin{array}{l}\text { Productivity: } \\
\text { Number of } \\
\text { weighted visits } \\
\text { per enrolled }\end{array}$ & 0.004 & -0.032 & -0.040 & -0.053 & 0.049 & -0.003 & $0.139 *$ \\
\hline $\begin{array}{l}\text { Background of } \\
\text { managing } \\
\text { director } \\
(\mathrm{GP}=1)\end{array}$ & $0.157 * *$ & $0.135^{*}$ & $0.124^{*}$ & 0.089 & $0.195 * *$ & $0.139^{*}$ & $0.141^{*}$ \\
\hline $\begin{array}{l}\text { Division of } \\
\text { labour: } \\
\text { Proportion GP } \\
\text { visits }\end{array}$ & $0.133^{*}$ & $0.144^{*}$ & $0.139 *$ & 0.062 & $0.253 * *$ & $0.163 * *$ & $0.168 * *$ \\
\hline $\begin{array}{l}\text { Efficiency: } \\
\text { payment per } \\
\text { weighted visit }\end{array}$ & -0.112 & -0.032 & -0.007 & -0.049 & -0.093 & -0.055 & $-0.224 * *$ \\
\hline $\begin{array}{l}\text { Process: } \\
\text { continuity in } \\
\text { GP visits }\end{array}$ & $0.335 * *$ & $0.283 * *$ & $.0280 * *$ & $0.321 * *$ & $0.463 * *$ & $0.339 * *$ & $0.311^{* *}$ \\
\hline $\begin{array}{l}\text { Process: } \\
\text { influenza } \\
\text { vaccination } \\
\text { coverage }\end{array}$ & $0.362 * *$ & $0.310 * *$ & $0.309 * *$ & $0.401 * *$ & $0.286 * *$ & $0.356^{* *}$ & $0.321 * *$ \\
\hline $\begin{array}{l}\text { Process: } \\
\text { prescription of } \\
\text { penicillin V }\end{array}$ & -0.062 & -0.023 & 0.005 & -0.086 & -0.041 & -0.027 & -0.050 \\
\hline $\begin{array}{l}\text { Process: } \\
\text { prescription of } \\
\text { quinolones }\end{array}$ & -0.012 & -0.031 & -0.081 & -0.024 & -0.082 & -0.048 & -0.074 \\
\hline $\begin{array}{l}\text { Process: } \\
\text { harmful drugs } \\
\text { to elderly }\end{array}$ & -0.103 & -0.011 & -0.086 & -0.082 & -0.005 & -0.051 & -0.016 \\
\hline Year: 2018 & -0.044 & -0.070 & -0.058 & -0.099 & -0.038 & -0.109 & $-0.135^{*}$ \\
\hline Year: 2019 & 0.044 & 0.070 & 0.058 & 0.099 & 0.038 & 0.109 & $0.135^{*}$ \\
\hline
\end{tabular}

** Pearson's Correlation is significant at the 0.01 level (2-tailed). * Pearson's Correlation is significant at the 0.05 level (2-tailed). 
Table 3: Regression models with PREMs as dependent variable

\begin{tabular}{|c|c|c|c|c|c|c|c|}
\hline & $\begin{array}{l}\text { Overall } \\
\text { impression }\end{array}$ & $\begin{array}{l}\text { Emotional } \\
\text { support }\end{array}$ & $\begin{array}{l}\text { Patient } \\
\text { involvement }\end{array}$ & $\begin{array}{l}\text { Respect } \\
\text { and } \\
\text { responsive- } \\
\text { ness }\end{array}$ & $\begin{array}{l}\text { Continuity } \\
\text { and } \\
\text { coordination }\end{array}$ & Information & Accessibility \\
\hline & Coefficient & Coefficient & Coefficient & Coefficient & Coefficient & Coefficient & Coefficient \\
\hline $\begin{array}{l}\text { Ownership } \\
\text { (Private PCC=1) }\end{array}$ & -0.075 & -1.138 & -0.968 & 0.014 & 1.207 & -0.598 & -0.234 \\
\hline PCC list size & 0.000 & $8.170^{\mathrm{E}-5}$ & $7.454^{\mathrm{E}-5}$ & $6.014^{\mathrm{E}-5}$ & $7.837^{\mathrm{E}-5}$ & $4.182^{\mathrm{E}-6}$ & 0.000 \\
\hline $\begin{array}{l}\text { Patient mix: } \\
\text { Socioeconomic } \\
\text { deprivation } \\
\text { (CNI) }\end{array}$ & -2.041 & -1.636 & 0.072 & $-3.427 * *$ & 1.051 & -0.739 & -1.014 \\
\hline $\begin{array}{l}\text { Patient mix: } \\
\text { Proportion on } \\
\text { PCC list aged } \\
\geq 75\end{array}$ & -19.384 & -24.970 & $-34.131 * *$ & -17.381 & -20.659 & $-30.217 * *$ & -15.562 \\
\hline $\begin{array}{l}\text { Background of } \\
\text { managing } \\
\text { director }(\mathrm{GP}=1)\end{array}$ & 1.322 & 0.808 & 0.788 & 0.100 & 0.931 & 0.819 & 1.124 \\
\hline $\begin{array}{l}\text { Division of } \\
\text { labour: } \\
\text { Proportion GP } \\
\text { visits }\end{array}$ & $12.769 * *$ & $10.672 *$ & $7.541^{*}$ & $7.142 *$ & $16.560 * * *$ & $9.578 * *$ & $9.766^{* *}$ \\
\hline $\begin{array}{l}\text { Efficiency: } \\
\text { Payment per } \\
\text { weighted visit }\end{array}$ & -0.001 & 0.000 & 0.000 & 0.000 & -.0001 & 0.000 & $-0.002 * *$ \\
\hline $\begin{array}{l}\text { Process: } \\
\text { continuity in GP } \\
\text { visits }\end{array}$ & $11.786^{* * *}$ & $11.321 * * *$ & $9.626 * * *$ & $7.944 * * *$ & $22.321 * * *$ & $10.120 * * *$ & $6.453 * * *$ \\
\hline $\begin{array}{l}\text { Process: } \\
\text { influenza } \\
\text { vaccination } \\
\text { coverage }\end{array}$ & $24.293 * * *$ & $21.724 * *$ & $23.165^{* *}$ & $13.521 * *$ & $29.070 * * *$ & $21.968 * * *$ & $15.754 * *$ \\
\hline $\begin{array}{l}\text { Process: } \\
\text { prescription of } \\
\text { penicillin V }\end{array}$ & -1.877 & 0.310 & -0.856 & -1.982 & -1.946 & -2.700 & -2.227 \\
\hline $\begin{array}{l}\text { Process: } \\
\text { prescription of } \\
\text { quinolones }\end{array}$ & -9.315 & -10.810 & -13.780 & -10.310 & -13.396 & -9.850 & -12.942 \\
\hline $\begin{array}{l}\text { Process: harmful } \\
\text { drugs to elderly } \\
\text { (DDD) }\end{array}$ & $-9.186^{\mathrm{E}-5}$ & $-1.767^{\mathrm{E}-6}$ & $-9.110^{\mathrm{E}-5}$ & $-3.919^{\mathrm{E}-5}$ & $-7.435^{\mathrm{E}-5}$ & $-8.398^{\mathrm{E}-5}$ & $-4.790^{\mathrm{E}-5}$ \\
\hline $\begin{array}{l}\text { Year effect } \\
(2019=0 / \\
2018=1)\end{array}$ & -0.110 & -0.023 & -0.351 & -.0679 & 0.790 & -1.022 & $-1.191^{*}$ \\
\hline (Constant) & $68.626^{* * *}$ & $65.964 * * *$ & $70.570 * * *$ & $82.226 * * *$ & $47.682 * * *$ & $70.241 * * *$ & $81.619^{* * *}$ \\
\hline Adjusted R2 & 0.339 & 0.226 & 0.228 & 0.310 & 0.411 & 0.319 & 0.446 \\
\hline $\begin{array}{l}\mathrm{N} \text { (number of } \\
\text { PCC year } \\
\text { observations) }\end{array}$ & 281 & 281 & 281 & 281 & 281 & 281 & 281 \\
\hline
\end{tabular}

Robust standard errors are used in all models.

Dummy-variables for municipalities and year are included in all models to control for structural differences and year effects.

$* * *, * *$ and $*$ denote statistical significance at the $0.1,1$ and $5 \%$-level. 


\section{Discussion}

This study adds to previous research on variation in patients' experiences with primary care by including a fairly broad set of indicators in the analysis. The sample was limited to observations from one Swedish region. Therefore, it was possible to include several factors that are comparable across PCCs in the analysis, while controlling for structural differences. The results show that patients' experiences were primarily related to organisation and processes of work, i.e. the division of labour, continuity in GP visits and adherence to guidelines regarding treatment of risk groups. Variables representing patient mix, PCC list size and ownership were insignificant in the regression models for most PREM-dimensions when including such factors. Another interesting observation is that the proxy measure of efficiency was significantly correlated with scores for one dimension only; the higher pay per weighted visit the lower accessibility. Hence, the results suggest that allocating more financial resources to providers does not necessarily result in better patient experiences. The results come with some limitations. First, the response rate in the NPS is low, which implies that the PREM-scores are not necessarily representative for all patients having visited a particular PCC. Second, the analysis of patients' experiences was carried out at PCC level. Preferences among individual patients might very well vary with respect to other factors than those captured in an analysis at the group level. Finally, the validity of the results would be better with more reliable data about the content of care and outcomes for patients rather than proxy measures of different aspects. However, such data is largely missing.

The bivariate analysis showed that private PCCs performed better with regard to the dimension continuity and coordination of care. When controlling for factors representing structural differences and the organisation and processes of work at PCCs, no differences across owner types could be detected. Patients seem to be equally satisfied with private and public PCCs as long as they are able to offer patients who make regular visits appointments with the same GP over time and provide safe care for risk groups. This finding, based on seven PREM-dimensions derived from the 2018 and 2019 NPS, differs from findings in a previous study, based on an analysis of five PREMdimensions derived from the 2010 NPS, i.e., the year after the choice reform (Glenngård 2013). This is an interesting finding, although the design of the NPS changed in 2015 which calls for a cautious interpretation of differences in results between the two periods. In the study based on 2010 NPS data from two regions, private PCCs performed better with regard to all PREM-dimensions on an overall level. Differences across owner types remained for the dimension continuity when controlling for patient mix, size and the division of labour. One reason that differences in patients' experiences across owner types could have decreased over time is that the patient mix have become more similar between public and private PCCs. In this study, the bivariate analysis showed that a high average CNI was associated with worse patient experiences for six out of seven PREM-dimensions. When controlling for other factors, the relationship persisted for the dimension respect and responsiveness. A high socioeconomic deprivation is associated with worse patient satisfaction also according to previous research in the Swedish context (Angelis et al 2021; Glenngård 2013; Glenngård and Anell 2017; 2018; Kandelake 2016) and elsewhere (Kontopantelis et al. 2010; Campbell et al. 2001b). Hence, if private PCCs are located in socioeconomic favourable areas to a higher extent than public ones, differences in patient mix could explain differences in patients' experiences across owner types. In the Swedish context, private PCCs that established in connection with the choice reform, in 2007-2010, are located in densely populated areas with overall low socioeconomic burden in the population (Swedish National Audit Office 2014; Burström et al 2017). There is some evidence that, in more recent years, private PCCs have to a larger extent established in more socioeconomically deprived areas. Anell et al (2018) conclude that risk-adjusted capitation affects private providers' establishment decisions. They found that risk-adjusted capitation, based on CNI, increases the supply of private PCCs in areas with unfavourable socioeconomic and demographic characteristics. Such risk-adjustment is practiced in almost all regions in Sweden, including Region Skåne. From a 
policy perspective, it is encouraging that current policies targeted at reducing inequalities in primary care seem to be successful in encouraging PCCs to establish in unfavourable areas (Anell et al 2018). However, according to the results in this study, risk-adjusted payment is apparently not enough to tackle variation in patients' experiences with regard to socioeconomic conditions. Despite the entry of new (private) providers in socioeconomically deprived areas ${ }^{1}$, such unwarranted variation remains, according to the results in this study. Further research is needed to confirm if this finding can be generalised to other parts of Sweden. Nevertheless, one conclusion in this study is that variation in patients' experiences with care in regards to differences in socioeconomic conditions remains a challenge for policy makers.

From an accountability perspective, the finding that patients' experiences, according to patient surveys, are associated more with variables that can be changed by providers themselves than factors that providers cannot control is encouraging. However, providers in Region Skåne, as well as in other regions, face a difficult task in satisfying patients' demands by offering a high proportion of GP visits and good continuity due to a persisting shortage of GPs. In connection with the choice reform, the number of PCCs increased by about 20 percent but the entry of new providers was not accompanied by a corresponding increase in GPs or other primary care staff. Rather, the existing scarce primary care workforce, in particular GPs, was spread out over more PCCs (Dietrichson et al 2020). Not only is a relatively small share of total resources for health allocated to primary care in Sweden. According to a recent study by the Swedish Agency for Health and Care Services Analysis (2020), GPs in Sweden also devote a smaller share of their working time to patients relative to GPs in other countries. The study included data from six other European countries and Australia, the United States, Canada and New Zealand. One reason behind the relatively low number of GP appointments is that team-based primary care is practiced in Sweden. The idea is that individuals should register with a PCC rather than with an individual GP (Anell 2011; Glenngård 2016; Olsen et al 2016). If Swedish GPs treat patients with worse conditions this might be one explanation as to why they have fewer appointments per hour. However, Swedish GPs also devote more time to administrative work and experience more work-related stress compared to GPs in other countries (Swedish Agency for Health and Care Services Analysis 2020). Moreover, also other staff categories experience work-related stress and that administrative work diverts attention from patients in Swedish primary care (Holmgren et al 2019; Hollman et al 2014). Hence, similar to Glenngård (2013) one conclusion in this study is that it is a challenge for providers to manage scarce human resources in a way that ensures continuity of care and satisfies patients' expectations and needs. A number of policy initiatives have been taken recently, e.g., targeted national grants to strengthen primary care and a new legislation targeting access, patient-centeredness and continuity in primary care (Ministry of Health and Social Affairs 2020). It remains to be seen if these initiatives are enough to tackle the situation with poor continuity and few GP appointments in Swedish primary care.

\section{Conclusions}

The results imply that, in Swedish primary care, variables that can be changed by providers themselves matter more for patients' experiences with care than factors that providers cannot control. The most significant associations were found between PREM-scores and proportion and continuity of GP visits and adherence to clinical guidelines regarding treatment of risk groups. However, it is a challenge for providers to offer a high proportion of visits with GPs and good continuity due to a persisting shortage of GPs in Sweden. Policy initiatives have been initiated and it remains to be seen if these are enough to tackle the situation. Moreover, current policies targeted

\footnotetext{
${ }^{1}$ In Region Skåne, seven private PCCs have been established during 2011-2019, whereof a majority in socioeconomically deprived areas. In 2018 and 2019, the average level of CNI was similar between public and private PCCs in the region (Personal communication Petra Widerkrantz, medical advisor Region Skåne 202004-16).
} 
at reducing inequalities in primary care seem to be a successful strategy to encourage PCCs to establish in unfavourable areas. However, the results indicate that poor socioeconomic conditions are associated with worse experiences with care, despite the entry of new providers in such areas. Variation in patients' experiences with regard to socioeconomic conditions remains a concern for policy makers.

\section{Acknowledgements}

The author is most grateful for helpful comments by Lina Maria Ellegård, Anders Anell, Ulf Gerdtham and Margareta Dackehag on earlier versions of this manuscript.

\section{References}

Anell, A. (2011). Choice and privatisation in Swedish primary care. Health Economics, Policy and Law, 6, 549-569.

Anell, A., Glenngård, A.H. and Merkur, S. (2012). Sweden: Health system review. Health Systems in Transition, 14(5), 1-161.

Anell, A., Dackehag, M. and Dietrichson, J. (2018). Does risk-adjusted payment influence primary care providers' decision on where to set up practices? BMC Health Services Research, 18,179.

Angelis, J., Glenngård, A.H. and Jordahl, H. (2021). Management practices and the quality of primary care. Public Money and Management, 41(3), 264-271.

Barnum, H., Kutzin, J. and Saxenian, H. (1995). Incentives and Provider Payment Methods. International Journal of Health Planning and Management, 10, 23-45.

Bevan, G., Helderman, J.K. and Wilsford, D. (2010) Changing choices in health care: implications for equity, efficiency and cost. Health economics policy and law, 5, 251267.

Bloom, N., Propper, C. and Seiler, S. (2015). The impact of competition on management quality: Evidence from public hospitals. Review of Economic Studies, 82(2), 457- 489.

Bloom, N. and Van Reenen, J. (2007) Measuring and explaining management practices across firms and countries. Quarterly Journal of Economics, 122(4), 1351-1408.

Burström, B., Burström, K., Nilsson, G., Tomson, G., Whitehead, M and Winblad, U. (2017). Equity aspects of the Primary Health Care Choice Reform in Sweden - a scoping review. International Journal for Equity in Health, 16, 29.

Campbell, J.L., Ramsay, J. and Green, J. (2001a) Practice size: impact on consultation length, workload, and patient assessment of care. British Journal of General Practice, 51(469), 644-650.

Campbell, J.L., Ramsay, J. and Green, J. (2001b). Age, gender, socioeconomic, and ethnic differences in patients' assessments of primary health care. Quality in Health Care, 10(2), 90-95.

Dietrichson, J., Ellegård, L.M. and Kjellsson, G. (2020). Patient choice, entry and quality of primary care: Evidence from Swedish reforms. Health Economics, 29(6), 716-730.

Ewbank, L., Thompson, J. and McKenna, H. (2017). NHS hospital bed numbers: Past, present, future. London: The King's Fund. 
Fredriksson, M., Blomqvist, P. and Winblad, U. (2014). Recentralizing healthcare through evidence-based guidelines - striving for national equity in Sweden. BMC Health Services Research, 14, 509.

Glenngård, A.H. (2013) Is patient satisfaction in primary care dependent on structural and organizational characteristics among providers? Findings based on data from the national patient survey in Sweden. Health Economics Policy and Law, 8(3), 317-333.

Glenngård, A.H. Experiences of Introducing a Quasi-Market in Swedish Primary Care: Fulfilment of Overall Objectives and Assessment of Provider Activities. Scandinavian Journal of Public Administration, 20(1), 72-86.

Glenngård, A.H. (2019). Pursuing the objectives of support to providers and external accountability through enabling controls - A study of governance models in Swedish primary care. BMC Health Services Research, 19, 114.

Glenngård, A.H. and Anell A. (2017). Does increased standardisation in health care mean less responsiveness towards individual patients' expectations? A register-based study in Swedish primary care. Sage open medicine, 25(5), 1-8.

Glenngård, A.H. and Anell, A. (2018). Process measures or patient reported experience measures (PREM) for comparing performance across providers? A study of measures related to access and continuity in Swedish primary care. Primary Health Care Research \& Development, 19, 23-32.

Health and Medical Services Act (Health Hälso- och sjukvårdslag) (2017:30).

Hollman, D., Lennartsson, S. and Rosengren, K. (2014). District nurses' experiences with the free-choice system in Swedish primary care. British Journal of Community Nursing, 19(1), 30-35.

Holmgren, K., Hensing, G., Bültmann, U., Hadzibajramovic, E. and Larsson, M.E. (2019). Does early identification of work-related stress, combined with feedback at GPconsultation, prevent sick leave in the following 12 months? A randomized controlled trial in primary health care. BMC Public Health, 19(1), 1110.

Institute of Medicine. (2001). Crossing the Quality Chasm: A New Health System for the 21st Century. Washington (DC): National Academies Press (US).

Jessup, R.L. (2007). Interdisciplinary versus multidisciplinary care teams: do we understand the difference? Australian Health Review, 31(3), 330-331.

Kandelaki, K., Marrone, G., Stålsby Lundborg, C., Schmidt, I. and Björkman, I. (2016). Patient-centredness as a quality domain in Swedish healthcare: results from the first national surveys in different Swedish healthcare settings. BMJ Open, 6(1).

Kontopantelis, E., Roland, M. and Reeves, D. (2010). Patient experience of access to primary care: identification of predictors in a national patient survey. BMC Family Practice, 11(61), 1-15.

Lamarche, P.A., Beaulieu, M., Pineault, R., Contandriopoulos, A., Denis, J. and Haggerty, J. (2003). Choices for Change: The Path for Restructuring Primary Healthcare Services in Canada. Canadian Health Services Research Foundation, New Brunswick Department of Health and Wellness, Saskatchewan Department of Health, Ministère de la santé et des services sociaux du Québec and Health Canada.

Le Grand, J. (2009). Choice and Competition in publicly funded health care. Health Economics Policy and Law, 4, 479-488.

Lövtrup, P. (2017). Rekordstor minskning av vårdplatserna 2016 [In Swedish]. Läkartidningen, 114, EP9T. 
Ministry of Health and Social Affairs (Socialdepartementet). (2020). Council on Legislation - The direction for a responsive and accessible care - A primary care reform (Lagrådsremiss - Inriktningen för en nära och tillgänglig vård - en primärvårdsreform). 2020-04-16.

Murante, A.M., Seghieri, C., Vainieri, M. and Schäfer, W. (2017). Patient-perceived responsiveness of primary care systems across Europe and the relationship with the health expenditure and remuneration systems of primary care doctors. Social Science \& Medicine, 186, 139-147.

National Board of Health and Welfare. (2009). Nationellt indikatorbibliotek för God vård i primärvården. För öppna jämförelser, uppföljning och utvärdering. Stockholm: National Board of Health and Welfare (NBHW). 2009-11-22.

National Board of Health and Welfare. https://www.socialstyrelsen.se/statistik-ochdata/oppna-jamforelser/ Accessed 2020-04-01.

Olsen, K.R., Anell, A., Häkkinen, U., Iversen, T., Ólafsdóttir, T. and Sutton, M. (2016). General practice in the Nordic countries. Nordic Journal of Health Economics, 4, 5667.

Pallant, J. (2007). SPSS Survival Manual 3rd edition: A Step By Step Guide to Data Analysis Using SPSS. Buckingham: Open University Press.

Prentice, G., Burgess, S. and Propper, C. (2007). Performance-pay in the public sector. London: Office of Manpower Economics.

Propper, C. (2012). Competition, Incentives and the English NHS. Health Economics, 21, 33-40.

Reid, R., MacWilliam, L., Roos, N.P., Bogdanovic, B. and Black, C. (1999). Measuring Morbidity in Populations: Performance of the Johns Hopkins Adjusted Clinical Group (ACG) Case-Mix Adjustment System in Manitoba. Manitoba Centre for Health Policy and Evaluation Department of Community Health Sciences Faculty of Medicine, University of Manitoba.

Starfield, B. (1998). Primary Care: Balancing Health Needs, Services and Technology. New York, Oxford University Press.

Sundquist, K., Malmström, M., Johansson, S.E. and Sundquist, J. (2003). Care Need Index, a useful tool for the distribution of primary health care resources. Journal of Epidemiological Community Health, 57, 347-352.

Region Skåne 2018. Definitioner och beskrivningar av kvalitetsindikatorer för vårdcentral i Hälsoval Skåne 2019.

Saltman, R.B., Rico, A., Boerma, W. (2006). Primary care in the Driver's seat? Organisational Reform in European Primary Care. Berkshire: Open University Press.

Scott, A. (2000). Economics of general practice. In Culyer, A.J. and Newhouse, J.P. (eds). Handbook of health economics, Volume 1 (pp 1181-183). Amsterdam: Elseiver Science.

Swedish Association of Local Authorities and Regions (SALAR) (2020). [Sveriges Kommuner och Regioner, SKR]: https://patientenkat.se/sv/english/ [24 April 2020]

Swedish National Audit Office. (2014). Riksrevisionen granskar: staten och vården. Primärvårdens styrning - efter behov eller efterfrågan? [In Swedish]. Stockholm: Riksrevisionen. 
Van den Hombergh, P., van Doorn-Klomberg, A., Campbell, S., Wensing, M. and Braspenning, J. (2016). Patient experiences with family medicine: a longitudinal study after the Dutch health care reforms in 2006. BMC Family Practice, 17, 118.

Swedish Agency for Health and Care Services Analysis. (2020). Vården ur primärvårdsläkarnas perspektiv 2019 [In Swedish]. Stockholm: Myndigheten för vårdanalys.

Yarnall, K.S.H., Østbye, T., Krause, K.M., Pollak, K.I., Gradison, M. and Michener J.L. (2009). Family physicians as team leaders: "time" to share the care. Preventing Chronic Disease, 6(2), A59.

(C) 2021 by the author(s). This article is an open access article distributed under the terms and conditions of the Creative Commons Attribution license (http://creativecommons.org/licenses/by/4.0/). 